\title{
Tea Polyphenols: A Natural Antioxidant Regulates Gut Flora to Protect the Intestinal Mucosa and Prevent Chronic Diseases
}

\author{
Xinzhou Wang ${ }^{1}$, Yanan Liu ${ }^{1}$, Zufang $\mathrm{Wu}^{1}{ }^{1}$, Peng Zhang ${ }^{2, *}$ and Xin Zhang ${ }^{1, *(\mathbb{C})}$ \\ 1 Department of Food Science and Engineering, Ningbo University, Ningbo 315211, China; \\ 15968052134@163.com (X.W.); liuyanan@nbu.edu.cn (Y.L.); zxdqqzyc@163.com (Z.W.) \\ 2 Department of Student Affairs, Xinyang Normal University, Xinyang 464000, China \\ * Correspondence: zp017083@163.com (P.Z.); zhangxin@nbu.edu.cn (X.Z.)
}

Citation: Wang, X.; Liu, Y.; Wu, Z.; Zhang, P.; Zhang, X. Tea Polyphenols: A Natural Antioxidant Regulates Gut Flora to Protect the Intestinal Mucosa and Prevent Chronic Diseases. Antioxidants 2022, 11, 253. https:// doi.org/10.3390/antiox11020253

Academic Editors: Thea Magrone and Luigi Santacroce

Received: 12 January 2022

Accepted: 27 January 2022

Published: 28 January 2022

Publisher's Note: MDPI stays neutral with regard to jurisdictional claims in published maps and institutional affiliations.

Copyright: (c) 2022 by the authors. Licensee MDPI, Basel, Switzerland. This article is an open access article distributed under the terms and conditions of the Creative Commons Attribution (CC BY) license (https:/ / creativecommons.org/licenses/by/ $4.0 /)$.

\begin{abstract}
The intestinal tract of a healthy human body hosts many microorganisms that are closely linked to all aspects of people's lives. The impact of intestinal flora on host health is no longer limited to the gut but can also affect every organ in the body through various pathways. Studies have found that intestinal flora can be altered by external factors, which provides new ideas for treating some diseases. Tea polyphenols (TP), a general term for polyphenols in tea, are widely used as a natural antioxidant in various bioactive foods. In recent years, with the progress of research, there have been many experiments that provide strong evidence for the ability of TP to regulate intestinal flora. However, there are very few studies on the use of TP to modify the composition of intestinal microorganisms to maintain health or treat related diseases, and this area has not received sufficient attention. In this review, we outline the mechanisms by which TP regulates intestinal flora and the essential role in maintaining suitable health. In addition, we highlighted the protective effects of $\mathrm{TP}$ on intestinal mucosa by regulating intestinal flora and the preventive and therapeutic effects on certain chronic diseases, which will help further explore measures to prevent related chronic diseases.
\end{abstract}

Keywords: tea polyphenols; antioxidant; intestinal flora; mucosa; chronic diseases

\section{Introduction}

According to available research data, the intestinal tract of a healthy adult hosts more than 100 trillion microorganisms, a number equivalent to all the human body cells $[1,2]$. The complex microbial-host network is established early in life, and it is now indisputable that gut microbes can influence the health of the human gut and even the brain [2-5]. Therefore, the intestine, which has many microorganisms, is also known as the "second brain" of the human body and plays an irreplaceable role in all aspects of the body's life activities [6,7]. The studies obtained so far have shown that the composition and structure of the intestinal microorganisms can be influenced by various factors, such as diet, physical activity, age, medication [8-11]. Among the many factors that affect intestinal flora, dietary factors have received the most attention because of their effectiveness, simplicity, and low cost. Studies have found that different diets will lead to some differences in the intestinal flora and the metabolites of intestinal microorganisms. For instance, the Mediterranean diet (MD), synonymous with a healthy diet, has received strong recommendations from experts because of its healthy nutritional structure [12,13]. Studies have shown that the microbial diversity in the intestinal tract of people on the MD pattern has increased, with an increase in the number of Bacteroides and Lactobacilli and a decrease in the number of Firmicutes; in addition, the MD effectively promotes the production of short-chain fatty acids (SCFAs) by intestinal microorganisms, which is of great help to human health $[14,15]$. Compared to the healthy MD, the Western-type diet (WD) with higher fat intake also affects intestinal flora and microbial metabolites. By comparing these two dietary patterns, scientists found only a slight difference between the two in terms of intestinal microbial diversity. Still, there is a significant difference between the two in terms of microbial metabolites, which leads 
to an increase in intestinal permeability in the WD, and this has laid a considerable risk for human health [14-16]. The secret of the health benefits of the MD lies in the fact that it is a high residue, low-fat diet, which is more conducive to improving the structure of the intestinal flora and promoting the production of beneficial metabolites [12,15]. Moreover, the nutritional structure of the MD contains a large number of bioactive components, such as polyphenols and polysaccharides $[17,18]$, whose effects on the intestinal flora deserve further study.

As a typical representative of bioactive substances, TP is an excellent natural antioxidant $[19,20]$. TP is the general name of polyphenolic compounds used in tea; TP has suitable antioxidant, antibacterial, anti-cancer, and other effects, so in various fields have been widely used $[20,21]$. As research progresses, researchers have discovered a strong relationship between TP and intestinal flora in recent years. Scientists have found that $\mathrm{TP}$ has a significant regulatory improvement effect on disordered intestinal flora. The composition structure of intestinal microorganisms has been changed under the influence of TP, through which TP has been widely used in anti-obesity and hypoglycemia [22-24]. However, based on the importance of intestinal flora in maintaining health, there should be a broader application for regulating intestinal flora through TP. Therefore, scientists are turning their attention to the protection of the intestinal mucosa. This idea opens a new door for TP to maintain the health of the body by regulating the intestinal flora and also provides new ideas for the prevention and treatment of some chronic diseases [25-27].

The intestinal mucosa, part of the immune system, plays an irreplaceable role in maintaining human health. The intestinal mucosa is in constant contact with external antigens and microorganisms, including harmful pathogenic microorganisms. As a critical barrier, the intestinal mucosa keeps pathogenic microorganisms outside and makes specific immune responses to protect the body from damage. In addition, the intestinal mucosa is a necessary pathway for microbial metabolites to enter the body. Therefore, we can visually see that the intestinal mucosa and intestinal microorganisms are closely related [28,29]. With the development of science and technology, our understanding of the intestinal mucosa and the effect of intestinal microorganisms on the intestinal mucosa has improved, and experimental results in recent years have confirmed that the intestinal mucosa and intestinal microorganisms are in an interactive relationship [30-32]. Thinking further, we can purposefully modulate the structural composition of microorganisms in the intestinal tract to play a protective role in the intestinal mucosa, strengthening our immunity and providing effective prevention of some related diseases.

Chronic diseases are a general term for diseases that do not constitute an infection and have a long-term accumulation of damage that forms a disease form. Since many people die from chronic diseases every year worldwide, the question of how to treat and prevent chronic diseases more effectively and conveniently is one that we must address [33]. Common chronic diseases include cardiovascular, metabolic, and neurodegenerative diseases; typical representatives include colorectal cancer (CRC), hyperlipidemia, diabetes, Alzheimer's disease, and inflammatory bowel disease (IBD). Past studies have confirmed a strong link between intestinal flora and various chronic diseases [34]. Given the ability of $\mathrm{TP}$ to regulate intestinal flora and the importance of intestinal microbes to the intestinal mucosa, scientists have begun to investigate the prevention and treatment of related chronic diseases by regulating intestinal flora $[25,35,36]$. To date, there has been some progress in this area of research, which provides a whole new scenario for the prevention and treatment of chronic diseases. In the future, through the regulation of daily dietary composition, the purposeful and appropriate addition of TP and other bioactive substances to regulate the intestinal flora and thus prevent and treat related chronic diseases will gradually become a reality.

The regulatory effect of TP on intestinal flora is still under further research. A variety of new functions are being discovered in the exploration, which can undoubtedly benefit the whole human society. In this review, we outline the mechanisms by which $\mathrm{TP}$ regulates intestinal flora and the vital role that intestinal flora plays in maintaining 
suitable health. In addition, we highlight the role of TP in protecting the intestinal mucosa, treating and preventing some chronic diseases by modulating the structural composition of microorganisms in the gut and provide an outlook on future developments in this field.

\section{The Relationship between Natural Antioxidant TP and Intestinal Flora}

2.1. TP

Tea as a beverage in people's daily lives has a long history. There are many kinds of tea; the most common varieties are green tea, black tea, and oolong tea. The world has a huge consumption of tea every year. Nowadays, tea has become an inseparable part of people's lives $[19,20]$. According to modern research, drinking tea is suitable for quenching thirst and very suitable for human health. The beneficial effects of tea on the human body are due to the high content of bioactive substances in tea, including TP, tea polysaccharides, theanine [37-40], of which TP is the most typical [22,39]. TP is composed of various phenolic compounds in tea leaves together, mainly including flavanols, flavanones, phenolic acids, anthocyanins, etc. Catechins, a group of compounds, are the most important and occupy a large proportion of the TP [41]. Catechins include (-)-epigallocatechin (EGC), (-)-epicatechin-3-gallate (ECG), (-)-epigallocatechin-3-gallate (EGCG) and (-)-epicatechin (EC) $[40,41]$. As a natural antioxidant, TP has powerful antioxidant and antibacterial abilities and can provide beneficial effects such as weight loss and blood sugar reduction [24,42,43]. Nowadays, TP has been widely used in the production of functional foods, edible films, and the treatment of related diseases $[24,43,44]$. $\mathrm{TP}$ as a research object still contains excellent potential; there are many mysteries that we have not discovered; in recent years, researchers have found that TP has a huge impact on the intestinal flora, based on the importance of intestinal flora for the living body, which opened a new door for the study of TP.

\subsection{Biotransformation of TP by Intestinal Flora}

In our daily life, we can take in TP from outside by drinking tea. The results of in vitro experiments simulating gastrointestinal digestion of TP show that the direct use of TP by the human body is very low, the absorption rate in the small intestine is only 10-20\%, and in addition, the investigation also found that after gastrointestinal ingestion of $\mathrm{TP}$, the antioxidant activity measured in the duodenal stage was significantly lower than that in the colonic stage, so it can be inferred that intestinal microorganisms play an extremely critical role in the metabolism and transformation of TP [45,46]. Past studies have confirmed that microorganisms will use a more significant portion of TP in the intestine for further metabolism, and these metabolites are partly absorbed into the blood and partly excreted in the feces [47]. Moreover, studies have shown that intestinal microorganisms can biotransform TP left in the colon, which is further transformed by decarboxylation, demethylation, and dehydroxylation by intestinal microorganisms, eventually producing smaller metabolites, such as phenolic acids [45,48,49]. The flavanols catechins (flavan-3-ols), which is the most important of the TP, undergoes C-ring fission and several dehydrogenations by the action of intestinal microorganisms, resulting in phenylpentanoic acid and phenyl- $\gamma$-valerolactones, which is then converted by intestinal microorganisms into various phenols and hydroxybenzoic acids [26,50,51]. Moreover, a study on the in vitro fermentation of EGCG by intestinal microorganisms showed that EGCG underwent sequential ester hydrolysis by intestinal microorganisms and was eventually degraded into a series of metabolites such as 3-(3', $4^{\prime}$-dihydroxyphenyl) propionic acid and 4-phenylbutyric acid [52]. These small metabolites can be absorbed by the intestinal mucosa into the portal circulation, flow to the liver, and then transfer to various body organs [53]. TP has excellent antioxidant, antibacterial and antiviral properties after intestinal microorganisms' transformation and plays an essential role in maintaining suitable health. 


\subsection{Effects of TP on Intestinal Flora}

As an antioxidant, TP has a particular antibacterial effect, which has a certain role in shaping the structure of the composition of microorganisms in the intestine and can affect the metabolites of intestinal microorganisms in the intestine. After research on animal models, human experiments, and in vitro fermentation, the experimental results show that $\mathrm{TP}$ can provide some stimulation to some beneficial bacteria in the intestine and inhibit the growth of harmful microorganisms, improving the composition structure of intestinal microorganisms. In addition, TP can also affect the type and content of microbial metabolites in the intestine, promoting the production of beneficial metabolites and reducing harmful metabolites, thereby further maintaining the health of the body [52,54-57].

So far, many experiments have demonstrated the effect of TP on the regulation of intestinal flora. Liu et al. [52] found that EGCG treatment stimulated beneficial bacteria such as Christensenellaceae, Bifidobacterium, and Bacteroides and inhibited pathogenic bacteria such as Bilophila, Enterobacteriaceae, Fusobacterium varium compared to the blank control group by in vitro fermentation experiments. In another experiment, Yuan et al. [54] provided strong evidence through human experiments that tea consumption can regulate human intestinal flora. According to studies in recent years, it was found that intestinal flora disorders accompany poor diet or inappropriate uses of drugs, and researchers found that this phenomenon can be better improved by using TP. The experiment by Li et al. [23] caused intestinal flora disorders in mice through the use of antibiotics, followed by oral administration of TP to observe the effect of TP on the regulation of disordered intestinal flora. The results showed that TP significantly alleviated the antibiotic-induced decrease in intestinal flora abundance and diversity and increased the relative abundance of probiotic bacteria such as Eubacterium, Roseburia, and Lactobacillus. In addition, TP can also be used to regulate intestinal flora disorders caused by high-fat diet. Wang et al. [58] found that mice fed a high-fat diet showed significant intestinal flora disorders, a decrease in the diversity of mouse intestinal microorganisms, and a significant increase in the Bacteroidetes to Firmicutes ratio, but subsequent modulation by TP significantly improved the abundance and diversity of microorganisms in the mouse intestine, and also reversed the high ratio of Bacteroidetes and Firmicutes caused by the high-fat diet. In addition, the experiment also revealed that after the conditioning with $\mathrm{TP}$, the mice showed a significant increase in the levels of butyric acid and acetic acid, both of which are important microbial metabolites. In another experiment, similar experimental results were obtained. The results of Li et al. [22] showed that TP reduced the relative abundance of Clostridiales and Synechococcus phylum and increased the relative abundance of thick-walled bacteria in the intestine of mice on a high-fat diet. So far, it is indisputable that TP can regulate intestinal flora. From the results, it is clear that this regulation is usually beneficial to human health.

TP has a regulatory effect on intestinal flora and influences the production of intestinal microbial metabolites, including SCFAs, lipopolysaccharides (LPS), and secondary bile acids. Through extensive animal experiments, the researchers found that the content of SCFAs in the intestine of animals treated with TP would be increased, and this phenomenon led to some new thoughts [52,59]. Ding et al. [60] found that six-brewed tea extract increased the abundance of several microorganisms that may produce SCFAs in the intestine of mice, including Lactobacillus, Bacteroides, and Ruminococcaceae, and this finding could provide a solid basis for the increased content of SCFAs in the intestine of animals treated with TP. Moreover, in another study, the researchers obtained the aqueous extract of black tea by steeping it in hot water, and the phenolic compounds were determined by high-performance liquid chromatography to test the inhibition of $\alpha$-glucosidase and $\alpha$-amylase activities. It was found that the higher the phenolic compounds, the better the inhibition effect on $\alpha$-glucosidase and $\alpha$-amylase activities. Therefore, it was concluded that TP had an inhibitory effect on $\alpha$-glucosidase and $\alpha$-amylase activities [61]. We can further consider that most of the SCFAs come from indigestible carbohydrates that reach the intestine through fermentation by intestinal microorganisms, and this experimental result represents that TP can allow more carbohydrates available to intestinal microorganisms to 
enter the intestine as substrates for the production of SCFAs. SCFAs not only strengthen the body's immune system but are also chemical mediators of intestinal communication with the brain and play a key role in maintaining the body's health $[62,63]$. Secondary bile acids, another important intestinal microbial metabolite, are obtained from primary bile acids that flow into the intestine through a series of transformations by intestinal microorganisms. Experiments by Sinha et al. [64] showed that disturbed intestinal flora inhibited the production of secondary bile acids and contributed to the development of intestinal inflammation. The ameliorative effect of TP on intestinal flora has been demonstrated by experimental results showing that TP increases the abundance of secondary bile acid-producing microorganisms in the intestine, such as Bacteroides and Bifidobacterium [52]. Secondary bile acids act on immune cells and enhance the body's immune system [65]. In addition to promoting the production of certain microbial metabolites, TP can also inhibit the production of certain metabolites, such as LPS. Studies have shown that excessive LPS can cause liver damage and related inflammatory responses, while TP can reduce the relative abundance of lipopolysaccharide-producing microorganisms, which can effectively reduce the accumulation of LPS and maintain human health $[66,67]$. The metabolites of intestinal flora have great potential for further research, and we can hypothesize whether, in the future, we can have beneficial effects on the human body by promoting or inhibiting the production of one or more metabolites? Further research is needed on this point.

In summary, the interaction between TP and intestinal microorganisms is shown in Figure 1. Interestingly, as research continues to develop, new findings have been made regarding the effects of TP on intestinal flora. Zhou et al. [68] found that TP was able to alter the microbial tricarboxylic acid (TCA) cycle and urea cycle in the rat intestine, and by doing so, improved the energy conversion efficiency of the rats, which was helpful in lowering blood glucose and lowering cholesterol levels. Research on the interaction between TP and intestinal flora continues to advance, and we look forward to another breakthrough in this area in the future.

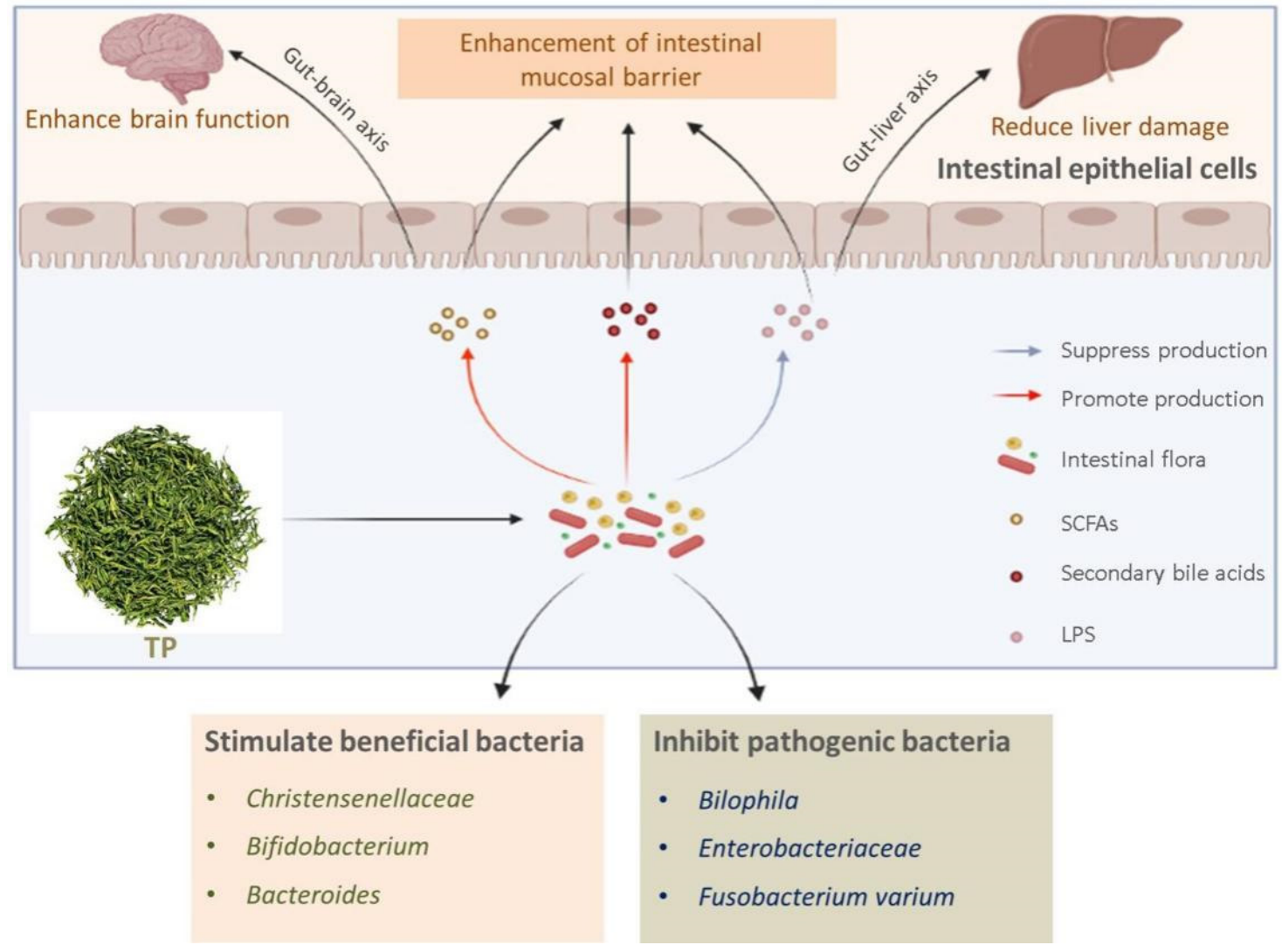

Figure 1. Effect of TP on intestinal flora. 


\section{TP Regulates Intestinal Flora for the Protection of Intestinal Mucosa}

\subsection{The Importance of Maintaining a Healthy Intestinal Mucosa}

As early as decades ago, scientists began to study the association between the intestinal mucosa and human health, and up to now, scientists have concluded that the intestinal mucosa is an important immune barrier in the human body and plays an irreplaceable role in maintaining human health [69-71]. The intestinal mucosal barrier consists of four main components, the biological barrier (mainly composed of beneficial microorganisms lodged in the intestine) [72,73], the mechanical barrier (mucus and intestinal epithelial cells (IECs), etc.) [74,75], the chemical barrier (Lysozyme, antimicrobial peptide, secretory phospholipase A2, etc.) [76] and the immune barrier (macrophages, secretory immunoglobulin A, etc.) $[77,78]$. Let us first look at the mechanical barriers in the intestinal barrier. The mechanical barrier consists of mucus, IECs, and cell junctions. The mucus layer in the intestine is composed of Mucin2 (MUC2) proteins secreted by goblet cells, which form a huge network structure in the intestine [79]. It was found that two layers of mucus usually cover the intestinal epithelium, the outer layer is sparse, and the inner layer is compact [80]. Through their study, Hansson et al. [79] found that the inner mucus layer is free of bacteria, which is good evidence that the mucus layer has a strong ability to block bacteria. IECs and cell junctions form the last line of defense of the mechanical barrier, which prevents pathogenic microorganisms and toxins from reaching here from entering the body and plays the role of absorbing water and nutrients [81]. Antimicrobial peptides, lysozyme, and other antimicrobial chemicals in the intestine together form a chemical barrier, and they are mainly found in the mucus layer, where they play a key antibacterial role [82]. Larsen et al. [83] showed that lysozyme-treated mice reduced the colitis response induced by dextran sulfate sodium (DSS) and effectively maintained intestinal microbial homeostasis compared to normal-fed control mice. In addition, when external harmful substances break through the mechanical and chemical barriers and cause infection, the IECs can send signals to the intrinsic immune cells in the intestinal mucosa, prompting the intestinal mucosa's immune barrier to function remove the invading harmful substances [84]. The intestinal epithelium and underlying lamina propria have a large number of immune cells, including mast cells, neutrophils, macrophages, T cells, and B cells, which are capable of making an immune response when they receive a signal to remove an antigen by recognizing it and either directly engulfing it or producing secretory immunoglobulin A $[85,86]$. The biological barrier is mainly composed of beneficial microorganisms lodged in the intestinal tract, which are large in number and can inhibit the growth and reproduction of harmful microorganisms by competing with them for living space with nutrients; in addition, the metabolites of beneficial microorganisms can also play the role of antibacterial and enhance the defense ability of the intestinal mucosa barrier $[87,88]$. There is much more to the connection between intestinal flora and the intestinal mucosa, as explained in more detail in the next section. In summary, the human intestinal tract maintains a dynamic "offensive and defensive balance," the importance of maintaining the health of the intestinal mucosa is self-evident; damage to the intestinal mucosa will lead to chronic colitis, colon cancer, and other chronic diseases, seriously endangering our health.

\subsection{The Relationship between Intestinal Microorganisms and Intestinal Mucosa}

It is not surprising that the intestinal flora has a close relationship with the intestinal mucosa, which is in an environment of direct contact with external microorganisms and naturally interacts with the intestinal flora, a view that scientists have long confirmed. Microorganisms in the intestine include beneficial commensal microorganisms and harmful pathogenic microorganisms. An incomplete intestinal mucosal barrier will increase the potential of pathogenic microorganisms to invade the organism. In one experiment, researchers inoculated mice with a defective intestinal mucus layer and wild-type mice with Citrobacter rodentium, a laxative pathogenic microorganism. They found that mice with a defective intestinal mucus layer had a higher mortality rate than wild-type mice, suggesting that the lack of a mucus layer leads to an increased chance of infection with pathogenic 
microorganisms [89]. For that matter, scientists have demonstrated that colonization of the intestinal tract by intestinal flora will affect the formation of the mucus barrier. By way of analogy, the experiments of Wrzosek et al. [90] found that B. thetaiotaomicron and F. prausnitzii in the gut can regulate the intestinal mucus layer by promoting the differentiation of goblet cell and the glycosylation of mucins, the production and main components of which we have already mentioned in the previous section. The interaction between the intestinal flora and the intestinal mucosal barrier is also reflected in the influence of intestinal microorganisms on the intestinal mucosal immune system. Past studies have found that intestinal flora can activate Toll-like receptors (TLRs), an important class of protein molecules involved in innate immunity that recognize microbes and activate the body to produce an immune response, playing an important role in maintaining gut homeostasis [91,92]. Activation of TLRs triggers the myeloid differentiation primary response protein MYD88 and further leads to the activation of the transcription factor nuclear factor $\kappa \mathrm{B}(\mathrm{NF}-\kappa \mathrm{B})$, an important nuclear transcription factor in cells that controls the expression of regulatory genes such as inflammation, immunity, and cell proliferation [93,94]. Danne et al. [95] found that Helicobacter hepaticus, a commensal microorganism in the mouse intestine, induces early IL-10 production by macrophages in the intestine and interacts with the receptor TLR2 to exert some anti-inflammatory effects. In addition, the metabolites of intestinal microorganisms have a significant impact on the intestinal mucosal barrier.

By using non-absorbable but fermentable dietary fiber in the intestine, intestinal microorganisms further metabolize it to produce metabolites of SCFAs, commonly including butyric acid, acetic acid, and propionic acid [96,97]. SCFAs play an essential role in maintaining the normal function of the intestinal mucosa. Most intuitively, SCFAs provide energy and maintain the homeostasis of IECs [98,99]. In contrast, the role played by SCFAs in the intestinal immune system has attracted more attention. In the intestine, SCFAs play a role in regulating intestinal mucosal immunity mainly by stimulating $\mathrm{G}$ protein-coupled receptors (GPR) on IECs and T cells [100]. Kim et al. [101] performed an experiment in which mice deficient in GPR41, GPR43 and control mice were induced to develop an inflammatory response and fed SCFAs. The experiment results revealed that SCFAs activated GPR41 and GPR43 on IECs and, in turn, activated the value-added protein kinase signaling pathway, which induced the production of chemokines and cytokines during the immune response and helped mice cope with inflammation. Furthermore, studies on butyric acid found that butyric acid can promote regulatory $\mathrm{T}$ cells by inducing tolerogenic dendritic cells (DCs) [102]. Thus, SCFAs, as important intestinal microbial metabolites, also maintain a close relationship with the intestinal mucosa.

Symbiotic microorganisms in the gut serve as an important biological barrier in the intestinal mucosal barrier, and the relationship between intestinal microorganisms and intestinal mucosa is shown in Figure 2. Of course, although we have made many breakthroughs in this field, there are still many uncharted areas waiting to be explored. We need to think further about what are the hidden associations between intestinal flora and intestinal mucosa that we have not noticed, such as whether intestinal microbes can interact with immune cells that we have not noticed or whether we can use a bioactive substance to purposefully modulate intestinal flora and strengthen the defenses of the intestinal mucosa.

\subsection{Benefits of TP on Intestinal Mucosa by Intestinal Microbial Structure}

The importance of the intestinal mucosa has been known for a long time, and scientists have started long research to discover ways to improve it. In their exploration, scientists found a close relationship between intestinal flora and intestinal mucosa and began to improve intestinal mucosa by regulating intestinal flora. Researchers found that among the various substances that can regulate intestinal flora, TP has numerous advantages, which have attracted the widespread attention of scientists. There is a follow-up further research. 


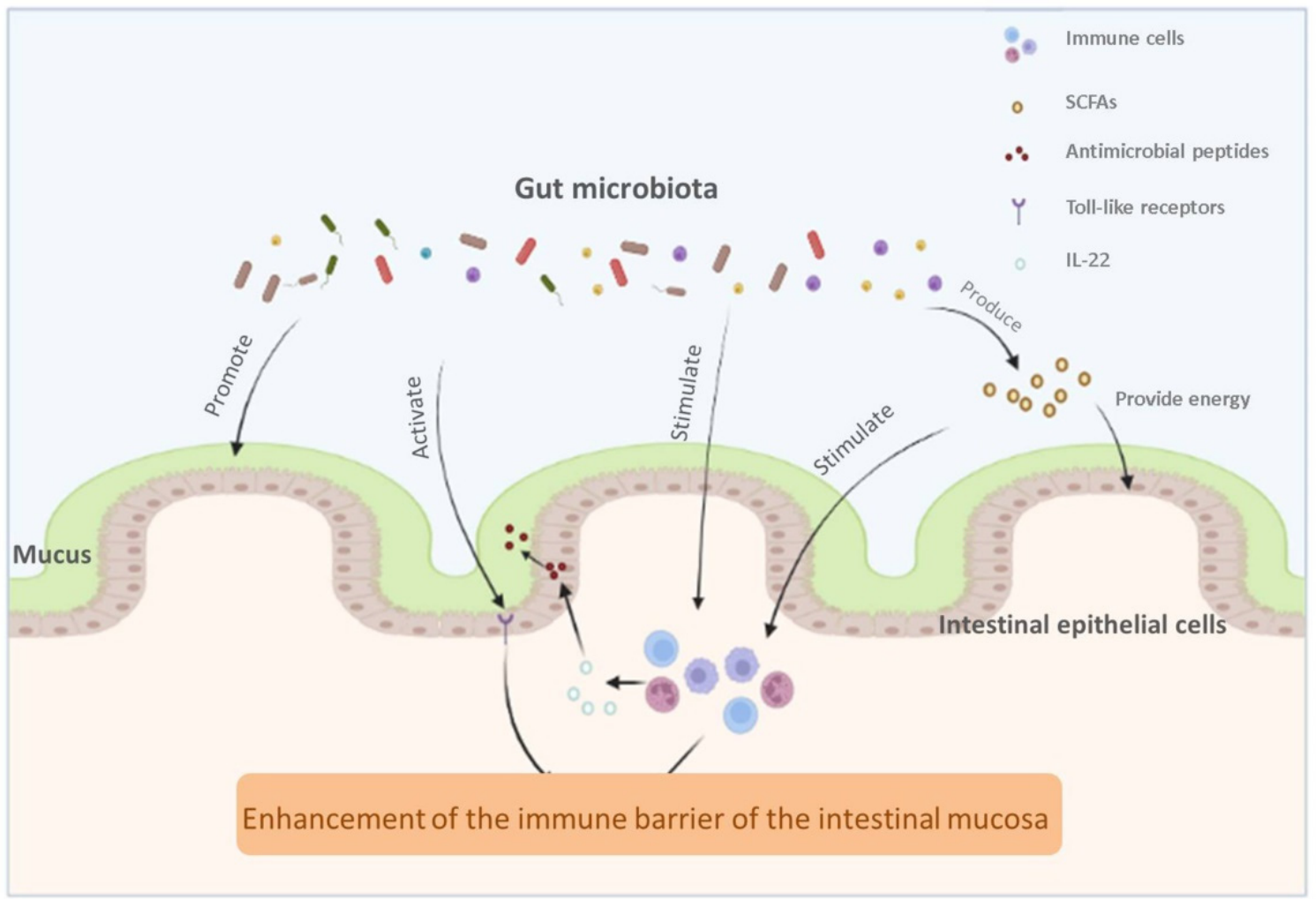

Figure 2. The relationship between intestinal microbiota and intestinal mucosa.

Past studies have pointed out that TP themselves are helpful for the protection of intestinal mucosa; TP can inhibit the generated lipid peroxide radicals, generate less active polyphenol radicals, and terminate the oxidation chain reaction of free radicals. In addition, TP can also improve superoxide dismutase, glutathione peroxidase, and many other antioxidant enzymes, more efficient in removing free radicals $[103,104]$. The experiments of Grzybowska-Chlebowczyk et al. [105] pointed out that the presence of free radicals is an important factor in triggering IBD. Another investigation showed that Java tea extract effectively scavenged free radicals in mice induced by a high-fat diet and played a protective role against oxidative damage in the intestine of mice [106], so it can be inferred that the effect of TP in removing free radicals can protect the intestinal mucosa from oxidative damage and effectively prevent the occurrence of intestinal inflammation. Nowadays, scientists have turned their attention to intestinal microorganisms, which are closely related to the intestinal mucosa, expecting that the regulatory effect of TP on the intestinal microorganisms can produce some protection for the intestinal mucosa.

Through scientists' ongoing efforts, new discoveries have been made on the role of TP in protecting the intestinal mucosa by affecting intestinal microorganisms. Firstly, TP has a certain inhibitory effect on harmful microorganisms in the intestinal tract, it was pointed out that TP could inhibit the growth and toxic properties of Fusobacterium nucleatum in the intestine, which has been shown to be associated with the development of IBD, and the experimental results showed that TP could prevent the formation of Fusobacterium nucleatum biofilm and exert some inhibitory effect on the activity of the biofilm already formed, in addition, the study also indicated that TP was able to attenuate Fusobacterium nucleatummediated hemolysis and hydrogen sulfide production [107]. Secondly, TP can improve the disorder of intestinal flora and intestinal damage caused by pathogenic microorganisms. Zhang et al. [108] investigated the effects of TP on the regulation of intestinal flora disorders in Salmonella typhimurium-infected mice and the mechanism of reducing the damage to the intestinal tract. The experimental results showed that TP reduced inflammation and oxidative stress markers and increased the levels of antioxidant enzymes and tight junction proteins in mice, which effectively improved intestinal flora disorders and reduced the 
damage to intestinal mucosa. Finally, TP can promote the production of metabolites SCFAs by intestinal microorganisms, thus achieving protection of the intestinal mucosal barrier. Wu et al. [25] regulated the intestinal flora of mice by giving them oral EGCG, and the experimental results showed that the regulation by EGCG significantly increased the relative abundance of SCFAs-producing bacteria (such as Ackermania) and the production of SCFAs in the intestine of mice.

In summary, the effect of TP on intestinal microorganisms to protect the intestinal mucosa has been supported by numerous experimental results. In the future, based on the powerful antioxidant ability of TP and their effect on the regulation of intestinal flora, there will be highly effective products with TP as the primary raw material for the prevention or treatment of chronic colitis, colon cancer, and other chronic diseases closely related to the intestinal mucosa. In recent years, the research on the prevention and treatment of such chronic diseases with TP has made new progress and gradually become another new treatment option for patients with related diseases, which is undoubtedly a blessing for patients.

\section{Intestinal Flora Protects the Intestinal Mucosa to Prevent Related Chronic Diseases}

\subsection{Prevention of Chronic Colitis}

IBD is a common chronic inflammatory disease of the intestinal tract that includes mainly ulcerative colitis (UC) and Crohn's disease (CD) $[109,110]$. It has been reported that IBD is present worldwide, affecting millions of people worldwide, and is on the rise in countries with westernized lifestyles [111,112]. Even today, the causes of IBD are still unclear. Scientists generally believe that it is caused by multiple factors, mainly environmental, genetic, infectious, and immune factors. In recent studies, it was found that intestinal flora disorders are considered a new factor in the pathogenesis of IBD, which opens a breakthrough in the prevention and treatment of IBD [113]. Nowadays, IBD puts pressure on the health care system of every country, and the prevalence is increasing year by year, so how to effectively treat and prevent IBD has become a major problem that we urgently need to solve.

After a long period of research and exploration, it is known that abnormalities in the immune system of the intestinal mucosa are an important cause of the development of IBD. Given the protective impact of commensal microorganisms in the intestine on the intestinal mucosa and the destructive effect of harmful microorganisms, the treatment, and prevention of IBD by regulating the intestinal flora does have great research potential, and a large number of scientists are now researching this area. Stool samples are often used as a proxy for the microbial composition of the intestine, and studies have found some differences in the microbial communities of stool samples from healthy individuals compared to those from patients with IBD, as evidenced by significantly lower microbial diversity and differences in the composition and structure of microorganisms [114-116]. In an experiment that provides strong evidence that a therapeutic effect can be achieved in chronic colitis by regulating intestinal flora, Burrello et al. [117] investigated the effect of fecal microbiota transplantation (FMT) effects on immune-mediated immunity mucosal inflammatory pathways in chronic colitis. The experiment was conducted by using DSS to induce the development of colitis in mice (with symptoms similar to IBD), and then by having the mice orally consume mucus from regular biological donors and feces to modulate their intestinal flora; the experimental results showed that therapeutic FMT was able to reduce colonic inflammation by modulating the expression of pro-inflammatory genes, antimicrobial peptides, and mucins in mice suffering from chronic intestinal inflammation. Thus, they provided the conclusion that FMT can control chronic intestinal experimental colitis by inducing synergistic activation of anti-inflammatory immune pathways. In addition, metabolites of intestinal microorganisms, mainly SCFAs and secondary bile acids, have been shown to have a therapeutic and preventive effect on IBD. The protection of the intestinal mucosa by SCFAs and their role in the intestinal immune system make them closely associated with IBD. Studies have shown that SCFAs maintain intestinal epithelial home- 
ostasis by activating the inflammasome to produce IL-8 and also have an anti-inflammatory effect by modulating immune cells in the intestinal mucosal immune system [118-120] and that the production of SCFAs is an important marker of the maturation of the intestinal mucosal immune system [121]. It has been found that the oxidative damage to the intestinal mucosa of patients with UC is caused by insufficient levels of butyric acid, which can be produced by beneficial microorganisms such as Bifidobacterium and Lactobacillus in the intestine [122,123]. Interestingly, Ashton et al. [124] found that by examining the concentrations of SCFAs in stool samples from multiple IBD patients, the concentrations of SCFAs in stool from IBD patients did not show a consistent pattern compared to controls, with some patients showing an increase in both overall and relative concentrations and others showing a decrease in both overall and relative concentrations. The researchers speculate that this phenomenon is due to the varying severity of inflammation in the intestinal tract of the patients; the less severe the inflammation, the intestinal epithelium absorbs, the more SCFAs. This experiment suggests that more factors should be taken into account when investigating the association between SCFAs and IBD. The beneficial metabolites of intestinal flora go far beyond SCFAs; metabolites produced by intestinal flora metabolizing bile acids have also been shown to have some anti-inflammatory effects $[125,126]$. Thinking further, the wide variety of metabolites of intestinal flora, some of which we have not yet studied, may also have a therapeutic effect on IBD.

Today, drug therapy for IBD is still the primary method; there are some drugs through the regulation of intestinal flora to achieve the anti-inflammatory effect, such as mesalamine [127], but the drugs have certain side effects after long-term use, so scientists have long hoped to find an alternative to anti-inflammatory medications. From the perspective of regulating intestinal flora and protecting intestinal mucosa, TP has received attention. The therapeutic and preventive effects of TP on IBD are mainly reflected in the influence of certain signaling pathways involved in inflammation and the regulation of intestinal microorganisms. The protective effects of TP on the intestinal mucosa and the regulation of intestinal microorganisms have been described in detail above. In addition, as a natural antioxidant, TP has a number of advantages over common anti-inflammatory drugs. First of all, TP can be obtained directly from the diet, which is easy and fast to obtain. In addition, a study comparing TP with sulfasalazine, a drug commonly used to treat IBD patients, showed that TP had fewer side effects than sulfasalazine while playing an antiinflammatory role $[123,128]$. It is worth noting that although TP is beneficial to health, it should not be used excessively. For the general population, experts recommend that drinking 10 cups of green tea a day is appropriate [129]. The experiments by Evans et al. [130] suggest that the recurrence of Clostridium difficile infection may be associated with tea consumption and that excess TP can also cause a decrease in normal microorganisms in the intestine. Looking to the future, with increased publicity on the benefits of TP, more and more people will adopt the habit of drinking tea in moderation daily, which will effectively reduce the prevalence of IBD.

\subsection{Prevention of Colorectal Cancer}

With the continuous improvement of people's living standards, the prevalence of CRC is on the rise year by year worldwide. According to relevant reports, colon cancer is the second leading cause of cancer-related deaths worldwide, and how to effectively treat CRC is a problem we have to face [131]. The pathogenesis of CRC is complex and has not been studied so far. Still, there have been several breakthroughs in research on treatment and prevention in recent years.

Past studies have shown that intestinal flora and its metabolites play an important role in protecting the intestinal mucosal barrier and maintaining the balance of the intestinal environment, so it is not surprising to speculate that there is an association between intestinal microbes and the development of CRC. It has been pointed out that the intestinal flora composition of CRC patients is significantly different from that of normal people, as shown by the decrease in beneficial bacteria such as Faecalibacterium, Bifidobacterium, and 
the increase in Mogibacterium, Porphyromonas [132]. This study provides a strong scientific basis that the disturbance of intestinal flora is one of the causes of CRC; therefore, scientists have started to treat and prevent CRC by changing the composition of intestinal flora. Liu et al. [133] performed regulation by adding Clostridium butyricum during inflammation induction in mice, and the experimental results showed that the microbial composition of the intestine of mice was changed after regulation by Clostridium butyricum, and the abundance of beneficial bacteria increased significantly, and the inflammatory response in the intestine decreased, which effectively prevented the development of colon cancer. In addition, scientists have also found a link between intestinal flora and the innate immune sensor absent in melanoma 2 (AIM2). Studies have demonstrated that AIM2 prevents microbial dysbiosis in the gut and inhibits the uncontrolled proliferation of intestinal stem cells, effectively preventing the development of CRC $[134,135]$. Man et al. [135] found by $16 \mathrm{~S}$ rRNA gene sequencing analysis that the composition of intestinal flora was significantly different in wild-type (WT) and Aim $2^{-/-}$mice reared alone, with significantly increased levels of Akkermansia muciniphila and Anaeroplasma in Aim2 $2^{-/}$mice compared to WT mice, and the levels of Anaerostipes, Bifidobacterium, Flexispira, Prevotella, and Paraprevotellaspecies were decreased. Moreover, the experiments also used the propagation properties of the intestinal flora. They found that the number of tumors and cancer incidence was significantly lower in the colon of Aim2 $2^{-/}$mice co-housed with WT mice compared to Aim2 $2^{-/-}$mice housed alone. This experiment provides strong evidence that intestinal flora can interact with AMI2 to prevent CRC development.

Compared with traditional radiation therapy, the treatment and prevention of CRC by regulating intestinal flora have the advantages of being more economical, more convenient, and safer, but the effectiveness needs to be further studied. However, it certainly provides a new possibility for CRC treatment and prevention, and this treatment method is also more acceptable to people, which is of great significance to reduce the incidence of CRC.

\section{Conclusions}

As a natural antioxidant, TP can protect the intestinal mucosa, regulate intestinal flora, and promote the production of beneficial metabolites by intestinal microorganisms. The homeostasis of intestinal flora and the production of beneficial metabolites can effectively protect the intestinal mucosal barrier, enhance the immune defense of the intestinal mucosal barrier, and effectively prevent and treat IBD, CRC, and other related chronic diseases. The therapeutic approach of regulating intestinal flora through the use of TP has been noted to have several advantages over traditional treatments for IBD and CRC, but whether this method can replace the traditional method and achieve the same therapeutic effect requires more in-depth research.

Author Contributions: Conceptualization, Validation, Writing—original draft, X.W.; Writing—review and editing, Y.L. and Z.W.; Supervision, Writing-original draft, P.Z.; Supervision, Writing—review and editing, X.Z. All authors have read and agreed to the published version of the manuscript.

Funding: This work was supported by the Key Research and development program of Zhejiang Province, grant number 2020C02037, and the Ningbo Natural Science Foundation, grant number 2021J107.

Institutional Review Board Statement: The study did not involve humans or animals.

Informed Consent Statement: Not applicable.

Data Availability Statement: The data presented in this study are available in review.

Conflicts of Interest: The authors declare no conflict of interest. 


\section{References}

1. Rinninella, E.; Raoul, P.; Cintoni, M.; Franceschi, F.; Miggiano, G.A.D.; Gasbarrini, A.; Mele, M.C. What is the healthy gut microbiota composition? A changing ecosystem across age, environment, diet, and diseases. Microorganisms 2019, 7, 14. [CrossRef] [PubMed]

2. Larsen, O.F.A.; Claassen, E. The mechanistic link between health and gut microbiota diversity. Sci. Rep. 2018, 8, 2183. [CrossRef] [PubMed]

3. Olivares, M.; Neyrinck, A.M.; Potgens, S.A.; Beaumont, M.; Salazar, N.; Cani, P.D.; Bindels, L.B.; Delzenne, N.M. The DPP-4 inhibitor vildagliptin impacts the gut microbiota and prevents disruption of intestinal homeostasis induced by a Western diet in mice. Diabetologia 2018, 61, 1838-1848. [CrossRef] [PubMed]

4. Tengeler, A.C.; Dam, S.A.; Wiesmann, M.; Naaijen, J.; van Bodegom, M.; Belzer, C.; Dederen, P.J.; Verweij, V.; Franke, B.; Kozicz, T.; et al. Gut microbiota from persons with attention-deficit/hyperactivity disorder affects the brain in mice. Microbiome 2020, 8, 44 [CrossRef] [PubMed]

5. Yang, C.; Qu, Y.; Fujita, Y.; Ren, Q.; Ma, M.; Dong, C.; Hashimoto, K. Possible role of the gut microbiota-brain axis in the antidepressant effects of (R)-ketamine in a social defeat stress model. Transl. Psychiatry 2017, 7, 1294. [CrossRef]

6. Bilal, A. Gut-microbiota-brain-axis, leaky gut, leaky brain: Pathophysiology of second brain aging and Alzheimer's disease- a neuroscientific riddle. Pharm. Biosci. J. 2019, 7, 29-37. [CrossRef]

7. $\mathrm{Hu}, \mathrm{X}$.; Li, S.; Fu, Y.; Zhang, N. Targeting gut microbiota as a possible therapy for mastitis. Eur. J. Clin. Microbiol. Infect. Dis. 2019, 38, 1409-1423. [CrossRef]

8. Zhang, X.; Zhong, H.; Li, Y.; Shi, Z.; Ren, H.; Zhang, Z.; Zhou, X.; Tang, S.; Han, X.; Lin, Y.; et al. Sex- and age-related trajectories of the adult human gut microbiota shared across populations of different ethnicities. Nat. Aging 2021, 1, 87-100. [CrossRef]

9. Sutcliffe, S.G.; Shamash, M.; Hynes, A.P.; Maurice, C.F. Common oral medications lead to prophage induction in bacterial isolates from the human gut. Viruses 2021, 13, 455. [CrossRef]

10. Pedersini, P.; Turroni, S.; Villafane, J.H. Gut microbiota and physical activity: Is there an evidence-based link? Sci. Total Environ. 2020, 727, 138648. [CrossRef]

11. Sakkas, H.; Bozidis, P.; Touzios, C.; Kolios, D.; Athanasiou, G.; Athanasopoulou, E.; Gerou, I.; Gartzonika, C. Nutritional status and the influence of the vegan diet on the gut microbiota and human health. Medicina 2020, 56, 88. [CrossRef] [PubMed]

12. Barnard, N.D.; Alwarith, J.; Rembert, E.; Brandon, L.; Nguyen, M.; Goergen, A.; Horne, T.; do Nascimento, G.F.; Lakkadi, K.; Tura, A.; et al. A mediterranean diet and low-fat vegan diet to improve body weight and cardiometabolic risk factors: A randomized, cross-over trial. J. Am. Coll. Nutr. 2021, 1-13. [CrossRef] [PubMed]

13. Barrea, L.; Muscogiuri, G.; Frias-Toral, E.; Laudisio, D.; Pugliese, G.; Castellucci, B.; Garcia-Velasquez, E.; Savastano, S.; Colao, A Nutrition and immune system: From the Mediterranean diet to dietary supplementary through the microbiota. Crit. Rev. Food Sci. Nutr. 2021, 61, 3066-3090. [CrossRef] [PubMed]

14. Merra, G.; Noce, A.; Marrone, G.; Cintoni, M.; Tarsitano, M.G.; Capacci, A.; De Lorenzo, A. Influence of mediterranean diet on human gut microbiota. Nutrients 2020, 13, 7. [CrossRef]

15. Barber, C.; Mego, M.; Sabater, C.; Vallejo, F.; Bendezu, R.A.; Masihy, M.; Guarner, F.; Espin, J.C.; Margolles, A.; Azpiroz, F. Differential effects of western and mediterranean-type diets on gut microbiota: A metagenomics and metabolomics approach. Nutrients 2021, 13, 2638. [CrossRef]

16. Nakayama, J.; Yamamoto, A.; Palermo-Conde, L.A.; Higashi, K.; Sonomoto, K.; Tan, J.; Lee, Y.K. Impact of westernized diet on gut microbiota in children on leyte island. Front. Microbiol. 2017, 8, 197. [CrossRef]

17. Nani, A.; Murtaza, B.; Sayed Khan, A.; Khan, N.A.; Hichami, A. Antioxidant and anti-inflammatory potential of polyphenols contained in mediterranean diet in obesity: Molecular mechanisms. Molecules 2021, 26, 985. [CrossRef]

18. van der Merwe, M. Gut microbiome changes induced by a diet rich in fruits and vegetables. Int. J. Food Sci. Nutr. 2021, 72, 665-669. [CrossRef]

19. Khan, N.; Mukhtar, H. Tea polyphenols in promotion of human health. Nutrients 2018, 11, 39. [CrossRef]

20. Yan, Z.; Zhong, Y.; Duan, Y.; Chen, Q.; Li, F. Antioxidant mechanism of tea polyphenols and its impact on health benefits. Anim. Nutr. 2020, 6, 115-123. [CrossRef]

21. Wang, S.T.; Cui, W.Q.; Pan, D.; Jiang, M.; Chang, B.; Sang, L.X. Tea polyphenols and their chemopreventive and therapeutic effects on colorectal cancer. World J. Gastroenterol. 2020, 26, 562-597. [CrossRef] [PubMed]

22. Li, Y.; Rahman, S.U.; Huang, Y.; Zhang, Y.; Ming, P.; Zhu, L.; Chu, X.; Li, J.; Feng, S.; Wang, X.; et al. Green tea polyphenols decrease weight gain, ameliorate alteration of gut microbiota, and mitigate intestinal inflammation in canines with high-fat-diet-induced obesity. J. Nutr. Biochem. 2020, 78, 108324. [CrossRef] [PubMed]

23. Li, J.; Chen, C.; Yang, H.; Yang, X. Tea polyphenols regulate gut microbiota dysbiosis induced by antibiotic in mice. Food Res. Int. 2021, 141, 110153. [CrossRef] [PubMed]

24. Chen, T.; Liu, A.B.; Sun, S.; Ajami, N.J.; Ross, M.C.; Wang, H.; Zhang, L.; Reuhl, K.; Kobayashi, K.; Onishi, J.C.; et al. Green tea polyphenols modify the gut microbiome in $\mathrm{db} / \mathrm{db}$ mice as co-abundance groups correlating with the blood glucose lowering effect. Mol. Nutr. Food Res. 2019, 63, e1801064. [CrossRef]

25. Wu, Z.; Huang, S.; Li, T.; Li, N.; Han, D.; Zhang, B.; Xu, Z.Z.; Zhang, S.; Pang, J.; Wang, S.; et al. Gut microbiota from green tea polyphenol-dosed mice improves intestinal epithelial homeostasis and ameliorates experimental colitis. Microbiome 2021, 9, 184. [CrossRef] [PubMed] 
26. Catalkaya, G.; Venema, K.; Lucini, L.; Rocchetti, G.; Delmas, D.; Daglia, M.; De Filippis, A.; Xiao, H.; Quiles, J.L.; Xiao, J.; et al. Interaction of dietary polyphenols and gut microbiota: Microbial metabolism of polyphenols, influence on the gut microbiota, and implications on host health. Food Front. 2020, 1, 109-133. [CrossRef]

27. Parrella, E.; Gussago, C.; Porrini, V.; Benarese, M.; Pizzi, M. From preclinical stroke models to humans: Polyphenols in the prevention and treatment of stroke. Nutrients 2020, 13, 85. [CrossRef]

28. McDermott, A.J.; Huffnagle, G.B. The microbiome and regulation of mucosal immunity. Immunology 2014, 142, 24-31. [CrossRef]

29. Perez-Lopez, A.; Behnsen, J.; Nuccio, S.P.; Raffatellu, M. Mucosal immunity to pathogenic intestinal bacteria. Nat. Rev. Immunol. 2016, 16, 135-148. [CrossRef]

30. Wang, L.; Zhu, L.; Qin, S. Gut microbiota modulation on intestinal mucosal adaptive immunity. J. Immunol. Res. 2019, 2019, 4735040. [CrossRef]

31. Li, B.; Liu, M.; Wang, Y.; Gong, S.; Yao, W.; Li, W.; Gao, H.; Wei, M. Puerarin improves the bone micro-environment to inhibit OVX-induced osteoporosis via modulating SCFAs released by the gut microbiota and repairing intestinal mucosal integrity. Biomed. Pharmacother. 2020, 132, 110923. [CrossRef] [PubMed]

32. Zou, J.; Liu, C.; Jiang, S.; Qian, D.; Duan, J.; Richardson Anthony, R. Cross talk between gut microbiota and intestinal mucosal immunity in the development of ulcerative colitis. Infect. Immun. 2021, 89, 9. [CrossRef] [PubMed]

33. Hong, B.; Jiang, J.D. Treating chronic diseases by regulating the gut microbiota. Engineering 2021, in press. [CrossRef]

34. Noce, A.; Marrone, G.; Di Daniele, F.; Ottaviani, E.; Wilson Jones, G.; Bernini, R.; Romani, A.; Rovella, V. Impact of gut microbiota composition on onset and progression of chronic non-communicable diseases. Nutrients 2019, 11, 1073. [CrossRef] [PubMed]

35. Man, A.W.C.; Xia, N.; Daiber, A.; Li, H. The roles of gut microbiota and circadian rhythm in the cardiovascular protective effects of polyphenols. Brit. J. Pharmacol. 2020, 177, 1278-1293. [CrossRef] [PubMed]

36. Ma, H.; Zhang, B.; Hu, Y.; Wang, J.; Liu, J.; Qin, R.; Lv, S.; Wang, S. Correlation analysis of intestinal redox state with the gut microbiota reveals the positive intervention of tea polyphenols on hyperlipidemia in high fat diet fed mice. J. Agric. Food Chem. 2019, 67, 7325-7335. [CrossRef]

37. Hidese, S.; Ogawa, S.; Ota, M.; Ishida, I.; Yasukawa, Z.; Ozeki, M.; Kunugi, H. Effects of L-theanine administration on stress-related symptoms and cognitive functions in healthy adults: A randomized controlled trial. Nutrients 2019, 11, 2362. [CrossRef]

38. Chen, G.; Xie, M.; Wan, P.; Chen, D.; Dai, Z.; Ye, H.; Hu, B.; Zeng, X.; Liu, Z. Fuzhuan brick tea polysaccharides attenuate metabolic syndrome in high-fat diet induced mice in association with modulation in the gut microbiota. J. Agric. Food Chem. 2018, 66, 2783-2795. [CrossRef]

39. Xing, L.; Zhang, H.; Qi, R.; Tsao, R.; Mine, Y. Recent advances in the understanding of the health benefits and molecular mechanisms associated with green tea polyphenols. J. Agric. Food Chem. 2019, 67, 1029-1043. [CrossRef]

40. Musial, C.; Kuban-Jankowska, A.; Gorska-Ponikowska, M. Beneficial properties of green tea catechins. Int. J. Mol. Sci. 2020, 21, 1744. [CrossRef]

41. Grzesik, M.; Naparlo, K.; Bartosz, G.; Sadowska-Bartosz, I. Antioxidant properties of catechins: Comparison with other antioxidants. Food Chem. 2018, 241, 480-492. [CrossRef] [PubMed]

42. Ma, Y.; Ding, S.; Fei, Y.; Liu, G.; Jang, H.; Fang, J. Antimicrobial activity of anthocyanins and catechins against foodborne pathogens Escherichia coli and Salmonella. Food Control 2019, 106, 106712. [CrossRef]

43. Henning, S.M.; Yang, J.; Hsu, M.; Lee, R.P.; Grojean, E.M.; Ly, A.; Tseng, C.H.; Heber, D.; Li, Z. Decaffeinated green and black tea polyphenols decrease weight gain and alter microbiome populations and function in diet-induced obese mice. Eur. J. Nutr. 2018, 57, 2759-2769. [CrossRef]

44. Dou, L.; Li, B.; Zhang, K.; Chu, X.; Hou, H. Physical properties and antioxidant activity of gelatin-sodium alginate edible films with tea polyphenols. Int. J. Biol. Macromol. 2018, 118, 1377-1383. [CrossRef] [PubMed]

45. Annunziata, G.; Maisto, M.; Schisano, C.; Ciampaglia, R.; Daliu, P.; Narciso, V.; Tenore, G.C.; Novellino, E. Colon bioaccessibility and antioxidant activity of white, green and black tea polyphenols extract after in vitro simulated gastrointestinal digestion. Nutrients 2018, 10, 1711. [CrossRef]

46. Tenore, G.C.; Campiglia, P.; Giannetti, D.; Novellino, E. Simulated gastrointestinal digestion, intestinal permeation and plasma protein interaction of white, green, and black tea polyphenols. Food Chem. 2015, 169, 320-326. [CrossRef]

47. Chen, H.; Sang, S. Biotransformation of tea polyphenols by gut microbiota. J. Funct. Foods 2014, 7, 26-42. [CrossRef]

48. Etxeberria, U.; Fernández-Quintela, A.; Milagro, F.I.; Aguirre, L.; Martínez, J.A.; Portillo, M.P. Impact of polyphenols and polyphenol-rich dietary sources on gut microbiota composition. J. Agric. Food Chem. 2013, 61, 9517-9533. [CrossRef]

49. Farag, M.A.; Abdelwareth, A.; Sallam, I.E.; El Shorbagi, M.; Jehmlich, N.; Fritz-Wallace, K.; Serena Schape, S.; Rolle-Kampczyk, U.; Ehrlich, A.; Wessjohann, L.A.; et al. Metabolomics reveals impact of seven functional foods on metabolic pathways in a gut microbiota model. J. Adv. Res. 2020, 23, 47-59. [CrossRef]

50. Zhao, Y.; Zhang, X. Interactions of tea polyphenols with intestinal microbiota and their implication for anti-obesity. J. Sci. Food Agric. 2020, 100, 897-903. [CrossRef]

51. Ozdal, T.; Sela, D.A.; Xiao, J.; Boyacioglu, D.; Chen, F.; Capanoglu, E. The reciprocal interactions between polyphenols and gut microbiota and effects on bioaccessibility. Nutrients 2016, 8, 78. [CrossRef]

52. Liu, Z.; de Bruijn, W.J.C.; Bruins, M.E.; Vincken, J.P. Reciprocal interactions between epigallocatechin-3-gallate (EGCG) and human gut microbiota in vitro. J. Agric. Food Chem. 2020, 68, 9804-9815. [CrossRef] 
53. Dey, P. Gut microbiota in phytopharmacology: A comprehensive overview of concepts, reciprocal interactions, biotransformations and mode of actions. Pharmacol. Res. 2019, 147, 104367. [CrossRef]

54. Yuan, X.; Long, Y.; Ji, Z.; Gao, J.; Fu, T.; Yan, M.; Zhang, L.; Su, H.; Zhang, W.; Wen, X.; et al. Green tea liquid consumption alters the human intestinal and oral microbiome. Mol. Nutr. Food Res. 2018, 62, e1800178. [CrossRef]

55. Chen, T.; Yang, C.S. Biological fates of tea polyphenols and their interactions with microbiota in the gastrointestinal tract: Implications on health effects. Crit. Rev. Food Sci. Nutr. 2020, 60, 2691-2709. [CrossRef]

56. Ma, H.; Hu, Y.; Zhang, B.; Shao, Z.; Roura, E.; Wang, S. Tea polyphenol-gut microbiota interactions: Hints on improving the metabolic syndrome in a multi-element and multi-target manner. Food Sci. Hum. Wellness 2022, 11, 11-21. [CrossRef]

57. Cheng, M.; Zhang, X.; Guo, X.J.; Wu, Z.F.; Weng, P.F. The interaction effect and mechanism between tea polyphenols and intestinal microbiota: Role in human health. J. Food Biochem. 2017, 41, e12415. [CrossRef]

58. Wang, L.; Zeng, B.; Liu, Z.; Liao, Z.; Zhong, Q.; Gu, L.; Wei, H.; Fang, X. Green tea polyphenols modulate colonic microbiota diversity and lipid metabolism in high-fat diet treated HFA mice. J. Food Sci. 2018, 83, 864-873. [CrossRef]

59. Yang, F.; Feng, B.; Niu, Y.J.; Hu, C.Y.; Meng, Y.H. Fu instant tea ameliorates fatty liver by improving microbiota dysbiosis and elevating short-chain fatty acids in the intestine of mice fed a high-fat diet. Food Biosci. 2021, 42, 101207. [CrossRef]

60. Ding, Q.; Zhang, B.; Zheng, W.; Chen, X.; Zhang, J.; Yan, R.; Zhang, T.; Yu, L.; Dong, Y.; Ma, B. Liupao tea extract alleviates diabetes mellitus and modulates gut microbiota in rats induced by streptozotocin and high-fat, high-sugar diet. Biomed. Pharmacother. 2019, 118, 109262. [CrossRef]

61. Striegel, L.; Kang, B.; Pilkenton, S.J.; Rychlik, M.; Apostolidis, E. Effect of black tea and black tea pomace polyphenols on alpha-glucosidase and alpha-amylase inhibition, relevant to type 2 diabetes prevention. Front. Nutr. 2015, 2, 3. [CrossRef] [PubMed]

62. Yang, W.; Yu, T.; Huang, X.; Bilotta, A.J.; Xu, L.; Lu, Y.; Sun, J.; Pan, F.; Zhou, J.; Zhang, W.; et al. Intestinal microbiota-derived short-chain fatty acids regulation of immune cell IL-22 production and gut immunity. Nat. Commun. 2020, 11, 4457. [CrossRef]

63. Lee, J.; d'Aigle, J.; Atadja, L.; Quaicoe, V.; Honarpisheh, P.; Ganesh, B.P.; Hassan, A.; Graf, J.; Petrosino, J.; Putluri, N.; et al. Gut microbiota-derived short-chain fatty acids promote poststroke recovery in aged mice. Circ. Res. 2020, 127, 453-465. [CrossRef]

64. Sinha, S.R.; Haileselassie, Y.; Nguyen, L.P.; Tropini, C.; Wang, M.; Becker, L.S.; Sim, D.; Jarr, K.; Spear, E.T.; Singh, G.; et al. Dysbiosis-Induced secondary bile acid deficiency promotes intestinal inflammation. Cell Host Microbe 2020, 27, 659-670.e5. [CrossRef]

65. Campbell, C.; McKenney, P.T.; Konstantinovsky, D.; Isaeva, O.I.; Schizas, M.; Verter, J.; Mai, C.; Jin, W.B.; Guo, C.J.; Violante, S.; et al. Bacterial metabolism of bile acids promotes generation of peripheral regulatory T cells. Nature 2020, 581, 475-479. [CrossRef]

66. Ding, Y.; Liu, P.; Chen, Z.L.; Zhang, S.J.; Wang, Y.Q.; Cai, X.; Luo, L.; Zhou, X.; Zhao, L. Emodin attenuates lipopolysaccharideinduced acute liver injury via inhibiting the TLR4 signaling pathway in vitro and in vivo. Front. Pharmacol. 2018, 9, 962.

67. Su, S.; Li, X.; Guo, X.; Zhou, R.; Li, M.; Ming, P.; Huang, Y.; Rahman, S.U.; Ding, H.; Feng, S.; et al. Tea polyphenols reducing lipopolysaccharide-induced inflammatory responses in RAW264.7 macrophages via NF-кB pathway. Chem. Res. Chin. Univ. 2019, 35, 1105-1110. [CrossRef]

68. Zhou, J.; Tang, L.; Shen, C.L.; Wang, J.S. Green tea polyphenols boost gut-microbiota-dependent mitochondrial TCA and urea cycles in Sprague-Dawley rats. J. Nutr. Biochem. 2020, 81, 108395. [CrossRef] [PubMed]

69. Noel, G.; Baetz, N.W.; Staab, J.F.; Donowitz, M.; Kovbasnjuk, O.; Pasetti, M.F.; Zachos, N.C. A primary human macrophageenteroid co-culture model to investigate mucosal gut physiology and host-pathogen interactions. Sci. Rep. 2017, 7, 45270. [CrossRef]

70. Riva, A.; Patel, V.; Kurioka, A.; Jeffery, H.C.; Wright, G.; Tarff, S.; Shawcross, D.; Ryan, J.M.; Evans, A.; Azarian, S.; et al Mucosa-associated invariant T cells link intestinal immunity with antibacterial immune defects in alcoholic liver disease. Gut 2018, 67, 918-930. [CrossRef]

71. Cinova, J.; De Palma, G.; Stepankova, R.; Kofronova, O.; Kverka, M.; Sanz, Y.; Tuckova, L. Role of intestinal bacteria in gliadin-induced changes in intestinal mucosa: Study in germ-free rats. PLoS ONE 2011, 6, e16169. [CrossRef] [PubMed]

72. Abrantes, F.A.; Nascimento, B.B.; Andrade, M.E.R.; de Barros, P.A.V.; Cartelle, C.T.; Martins, F.S.; Nicoli, J.R.; Arantes, R.M.E.; Generoso, S.V.; Fernandes, S.O.A.; et al. Treatment with bifidobacterium longum 5(1A) attenuates intestinal damage and inflammatory response in experimental colitis. Benef. Microbes 2020, 11, 47-57. [CrossRef] [PubMed]

73. Hou, Q.; Ye, L.; Liu, H.; Huang, L.; Yang, Q.; Turner, J.R.; Yu, Q. Lactobacillus accelerates ISCs regeneration to protect the integrity of intestinal mucosa through activation of STAT3 signaling pathway induced by LPLs secretion of IL-22. Cell Death Differ. 2018, 25, 1657-1670. [CrossRef] [PubMed]

74. Macierzanka, A.; Mackie, A.R.; Krupa, L. Permeability of the small intestinal mucus for physiologically relevant studies: Impact of mucus location and ex vivo treatment. Sci. Rep. 2019, 9, 17516. [CrossRef]

75. Ladinsky, M.S.; Araujo, L.P.; Zhang, X.; Veltri, J.; Galan-Diez, M.; Soualhi, S.; Lee, C.; Irie, K.; Pinker, E.Y.; Narushima, S.; et al. Endocytosis of commensal antigens by intestinal epithelial cells regulates mucosal T cell homeostasis. Science 2019, 363. [CrossRef]

76. Okumura, R.; Takeda, K. Maintenance of intestinal homeostasis by mucosal barriers. Inflamm. Regen. 2018, 38, 5. [CrossRef]

77. Quiros, M.; Nishio, H.; Neumann, P.A.; Siuda, D.; Brazil, J.C.; Azcutia, V.; Hilgarth, R.; O'Leary, M.N.; Garcia-Hernandez, V.; Leoni, G.; et al. Macrophage-derived IL-10 mediates mucosal repair by epithelial WISP-1 signaling. J. Clin. Investig. 2017, 127, 3510-3520. [CrossRef] 
78. Song, B.; Zheng, C.; Zha, C.; Hu, S.; Yang, X.; Wang, L.; Xiao, H. Dietary leucine supplementation improves intestinal health of mice through intestinal SIgA secretion. J. Appl. Microbiol. 2020, 128, 574-583. [CrossRef]

79. Hansson, G.C.; Johansson, M.E. The inner of the two Muc2 mucin-dependent mucus layers in colon is devoid of bacteria. Gut Microbes 2010, 1, 51-54. [CrossRef]

80. Ermund, A.; Schutte, A.; Johansson, M.E.; Gustafsson, J.K.; Hansson, G.C. Studies of mucus in mouse stomach, small intestine, and colon. I. Gastrointestinal mucus layers have different properties depending on location as well as over the Peyer's patches. Am. J. Physiol. Gastrointest. Liver Physiol. 2013, 305, G341-G347. [CrossRef]

81. Drolia, R.; Tenguria, S.; Durkes, A.C.; Turner, J.R.; Bhunia, A.K. Listeria adhesion protein induces intestinal epithelial barrier dysfunction for bacterial translocation. Cell Host Microbe 2018, 23, 470-484. [CrossRef] [PubMed]

82. Bel, S.; Hooper, L.V. Secretory autophagy of lysozyme in paneth cells. Autophagy 2018, 14, 719-721. [CrossRef] [PubMed]

83. Larsen, I.S.; Jensen, B.A.H.; Bonazzi, E.; Choi, B.S.Y.; Kristensen, N.N.; Schmidt, E.G.W.; Suenderhauf, A.; Morin, L.; Olsen, P.B.; Hansen, L.B.S.; et al. Fungal lysozyme leverages the gut microbiota to curb DSS-induced colitis. Gut Microbes 2021, 13, 1988836. [CrossRef] [PubMed]

84. Allaire, J.M.; Crowley, S.M.; Law, H.T.; Chang, S.Y.; Ko, H.J.; Vallance, B.A. The intestinal epithelium: Central coordinator of mucosal immunity. Trends Immunol. 2018, 39, 677-696. [CrossRef]

85. Lycke, N.Y.; Bemark, M. The regulation of gut mucosal IgA B-cell responses: Recent developments. Mucosal. Immunol. 2017, 10, 1361-1374. [CrossRef]

86. Ma, N.; Zhang, J.; Reiter, R.J.; Ma, X. Melatonin mediates mucosal immune cells, microbial metabolism, and rhythm crosstalk: A therapeutic target to reduce intestinal inflammation. Med. Res. Rev. 2020, 40, 606-632. [CrossRef]

87. Cui, H.; Cai, Y.; Wang, L.; Jia, B.; Li, J.; Zhao, S.; Chu, X.; Lin, J.; Zhang, X.; Bian, Y.; et al. Berberine regulates Treg/Th17 balance to treat ulcerative colitis through modulating the gut microbiota in the colon. Front. Pharmacol. 2018, 9, 571. [CrossRef]

88. Beaumont, M.; Portune, K.J.; Steuer, N.; Lan, A.; Cerrudo, V.; Audebert, M.; Dumont, F.; Mancano, G.; Khodorova, N.; Andriamihaja, M.; et al. Quantity and source of dietary protein influence metabolite production by gut microbiota and rectal mucosa gene expression: A randomized, parallel, double-blind trial in overweight humans. Am. J. Clin. Nutr. 2017, 106, 1005-1019. [CrossRef]

89. Roy, C.R.; Bergstrom, K.S.B.; Kissoon-Singh, V.; Gibson, D.L.; Ma, C.; Montero, M.; Sham, H.P.; Ryz, N.; Huang, T.; Velcich, A.; et al. Muc2 protects against lethal infectious colitis by disassociating pathogenic and commensal bacteria from the colonic mucosa. PLoS Pathog. 2010, 6, e1000902.

90. Wrzosek, L.; Miquel, S.; Noordine, M.L.; Bouet, S.; Chevalier-Curt, M.J.; Robert, V.; Philippe, C.; Bridonneau, C.; Cherbuy, C.; Robbe-Masselot, C.; et al. Bacteroides thetaiotaomicron and faecalibacterium prausnitziiinfluence the production of mucus glycans and the development of goblet cells in the colonic epithelium of a gnotobiotic model rodent. BMC Biol. 2013, 11, 61. [CrossRef]

91. Anthoney, N.; Foldi, I.; Hidalgo, A. Toll and toll-like receptor signalling in development. Development 2018, 145, 156018. [CrossRef] [PubMed]

92. Rose, W.A., 2nd; Sakamoto, K.; Leifer, C.A. TLR9 is important for protection against intestinal damage and for intestinal repair Sci. Rep. 2012, 2, 574. [PubMed]

93. Akira, S.; Takeda, K. Toll-like receptor signalling. Nat. Rev. Immunol. 2004, 4, 499-511. [CrossRef] [PubMed]

94. Zinatizadeh, M.R.; Schock, B.; Chalbatani, G.M.; Zarandi, P.K.; Jalali, S.A.; Miri, S.R. The nuclear factor kappa B (NF-kB) signaling in cancer development and immune diseases. Genes Dis. 2021, 8, 287-297. [CrossRef] [PubMed]

95. Danne, C.; Ryzhakov, G.; Martinez-Lopez, M.; Ilott, N.E.; Franchini, F.; Cuskin, F.; Lowe, E.C.; Bullers, S.J.; Arthur, J.S.C.; Powrie, F. A Large polysaccharide produced by helicobacter hepaticus induces an anti-inflammatory gene signature in macrophages. Cell Host Microbe 2017, 22, 733-745. [CrossRef]

96. Ahmadi, S.; Mainali, R.; Nagpal, R.; Sheikh-Zeinoddin, M.; Soleimanian-Zad, S.; Wang, S.; Deep, G.; Kumar Mishra, S.; Yadav, $\mathrm{H}$. Dietary polysaccharides in the amelioration of gut microbiome dysbiosis and metabolic diseases. Obes. Control Ther. 2017, 4. [CrossRef]

97. van der Beek, C.M.; Dejong, C.H.C.; Troost, F.J.; Masclee, A.A.M.; Lenaerts, K. Role of short-chain fatty acids in colonic inflammation, carcinogenesis, and mucosal protection and healing. Nutr. Rev. 2017, 75, 286-305. [CrossRef]

98. den Besten, G.; van Eunen, K.; Groen, A.K.; Venema, K.; Reijngoud, D.J.; Bakker, B.M. The role of short-chain fatty acids in the interplay between diet, gut microbiota, and host energy metabolism. J. Lipid Res. 2013, 54, 2325-2340. [CrossRef]

99. Kobayashi, M.; Mikami, D.; Kimura, H.; Kamiyama, K.; Morikawa, Y.; Yokoi, S.; Kasuno, K.; Takahashi, N.; Taniguchi, T.; Iwano, M. Short-chain fatty acids, GPR41 and GPR43 ligands, inhibit TNF- $\alpha$-induced MCP-1 expression by modulating p38 and JNK signaling pathways in human renal cortical epithelial cells. Biochem. Bioph. Res. Commun. 2017, 486, 499-505. [CrossRef]

100. Park, J.; Wang, Q.; Wu, Q.; Mao-Draayer, Y.; Kim, C.H. Bidirectional regulatory potentials of short-chain fatty acids and their G-protein-coupled receptors in autoimmune neuroinflammation. Sci. Rep. 2019, 9, 8837. [CrossRef]

101. Kim, M.H.; Kang, S.G.; Park, J.H.; Yanagisawa, M.; Kim, C.H. Short-chain fatty acids activate GPR41 and GPR43 on intestinal epithelial cells to promote inflammatory responses in mice. Gastroenterology 2013, 145, 396-406. [CrossRef] [PubMed]

102. Kaisar, M.M.M.; Pelgrom, L.R.; van der Ham, A.J.; Yazdanbakhsh, M.; Everts, B. Butyrate conditions human dendritic cells to prime type 1 regulatory $\mathrm{T}$ cells via both histone deacetylase inhibition and G protein-coupled receptor 109A signaling. Front. Immunol. 2017, 8, 1429. [CrossRef] [PubMed] 
103. Qian, Y.; Zhang, J.; Fu, X.; Yi, R.; Sun, P.; Zou, M.; Long, X.; Zhao, X. Preventive effect of raw liubao tea polyphenols on mouse gastric injuries induced by $\mathrm{HCl} /$ Ethanol via anti-oxidative stress. Molecules 2018, 23, 2848. [CrossRef]

104. Zhao, X.; Song, J.L.; Yi, R.; Li, G.; Sun, P.; Park, K.Y.; Suo, H. Comparison of antioxidative effects of insect tea and its raw tea (Kuding Tea) polyphenols in Kunming mice. Molecules 2018, 23, 204. [CrossRef] [PubMed]

105. Grzybowska-Chlebowczyk, U.; Wysocka-Wojakiewicz, P.; Jasielska, M.; Cukrowska, B.; Wiecek, S.; Kniazewska, M.; Chudek, J. Oxidative and antioxidative stress status in children with inflammatory bowel disease as a result of a chronic inflammatory process. Mediat. Inflamm. 2018, 2018, 4120973. [CrossRef] [PubMed]

106. Cai, X.; Xiao, C.; Xue, H.; Xiong, H.; Hang, Y.; Xu, J.; Lu, Y. A comparative study of the antioxidant and intestinal protective effects of extracts from different parts of Java tea (Orthosiphon stamineus). Food Sci. Nutr. 2018, 6, 579-584. [CrossRef] [PubMed]

107. Ben Lagha, A.; Haas, B.; Grenier, D. Tea polyphenols inhibit the growth and virulence properties of Fusobacterium nucleatum. Sci. Rep. 2017, 7, 44815. [CrossRef]

108. Zhang, L.; Gui, S.; Wang, J.; Chen, Q.; Zeng, J.; Liu, A.; Chen, Z.; Lu, X. Oral administration of green tea polyphenols (TP) improves ileal injury and intestinal flora disorder in mice with Salmonella typhimurium infection via resisting inflammation, enhancing antioxidant action and preserving tight junction. J. Funct. Foods 2020, 64, 103654. [CrossRef]

109. Ungaro, F.; Massimino, L.; Furfaro, F.; Rimoldi, V.; Peyrin-Biroulet, L.; D'Alessio, S.; Danese, S. Metagenomic analysis of intestinal mucosa revealed a specific eukaryotic gut virome signature in early-diagnosed inflammatory bowel disease. Gut Microbes 2019, 10, 149-158. [CrossRef]

110. Rubin, D.C.; Shaker, A.; Levin, M.S. Chronic intestinal inflammation: Inflammatory bowel disease and colitis-associated colon cancer. Front. Immunol. 2012, 3, 107. [CrossRef]

111. Ananthakrishnan, A.N.; Kaplan, G.G.; Ng, S.C. Changing global epidemiology of inflammatory bowel diseases: Sustaining health care delivery into the 21st century. Clin. Gastroenterol. Hepatol. 2020, 18, 1252-1260. [CrossRef] [PubMed]

112. Coward, S.; Clement, F.; Benchimol, E.I.; Bernstein, C.N.; Avina-Zubieta, J.A.; Bitton, A.; Carroll, M.W.; Hazlewood, G.; Jacobson, K.; Jelinski, S.; et al. Past and future burden of inflammatory bowel diseases based on modeling of population-based data. Gastroenterology 2019, 156, 1345-1353. [CrossRef] [PubMed]

113. Khan, I.; Ullah, N.; Zha, L.; Bai, Y.; Khan, A.; Zhao, T.; Che, T.; Zhang, C. Alteration of gut microbiota in inflammatory bowel disease (IBD): Cause or consequence? IBD treatment targeting the gut microbiome. Pathogens 2019, 8, 126. [CrossRef] [PubMed]

114. Gevers, D.; Kugathasan, S.; Denson, L.A.; Vazquez-Baeza, Y.; Van Treuren, W.; Ren, B.; Schwager, E.; Knights, D.; Song, S.J.; Yassour, M.; et al. The treatment-naive microbiome in new-onset Crohn's disease. Cell Host Microbe 2014, 15, 382-392. [CrossRef] [PubMed]

115. Samanta, A.K.; Torok, V.A.; Percy, N.J.; Abimosleh, S.M.; Howarth, G.S. Microbial fingerprinting detects unique bacterial communities in the faecal microbiota of rats with experimentally-induced colitis. J. Microbiol. 2012, 50, 218-225. [CrossRef]

116. Kolho, K.-L.; Korpela, K.; Jaakkola, T.; Pichai, M.V.A.; Zoetendal, E.G.; Salonen, A.; de Vos, W.M. Fecal microbiota in pediatric inflammatory bowel disease and its relation to inflammation. Off. J. Am. Coll. Gastroenterol. ACG 2015, 110, 921-930. [CrossRef]

117. Burrello, C.; Giuffre, M.R.; Macandog, A.D.; Diaz-Basabe, A.; Cribiu, F.M.; Lopez, G.; Borgo, F.; Nezi, L.; Caprioli, F.; Vecchi, M.; et al. Fecal microbiota transplantation controls murine chronic intestinal inflammation by modulating immune cell functions and gut microbiota composition. Cells 2019, 8, 517. [CrossRef] [PubMed]

118. Macia, L.; Tan, J.; Vieira, A.T.; Leach, K.; Stanley, D.; Luong, S.; Maruya, M.; Ian McKenzie, C.; Hijikata, A.; Wong, C.; et al. Metabolite-sensing receptors GPR43 and GPR109A facilitate dietary fibre-induced gut homeostasis through regulation of the inflammasome. Nat. Commun. 2015, 6, 6734. [CrossRef]

119. Chang, P.V.; Hao, L.; Offermanns, S.; Medzhitov, R. The microbial metabolite butyrate regulates intestinal macrophage function via histone deacetylase inhibition. Proc. Natl. Acad. Sci. USA 2014, 111, 2247-2252. [CrossRef]

120. Kim, M.; Qie, Y.; Park, J.; Kim, C.H. Gut microbial metabolites fuel host antibody responses. Cell Host Microbe 2016, $20,202-214$. [CrossRef]

121. Al Nabhani, Z.; Dulauroy, S.; Marques, R.; Cousu, C.; Al Bounny, S.; Dejardin, F.; Sparwasser, T.; Berard, M.; Cerf-Bensussan, N.; Eberl, G. A weaning reaction to microbiota Is required for resistance to immunopathologies in the adult. Immunity 2019, 50, 1276-1288. [CrossRef] [PubMed]

122. De Preter, V.; Arijs, I.; Windey, K.; Vanhove, W.; Vermeire, S.; Schuit, F.; Rutgeerts, P.; Verbeke, K. Impaired butyrate oxidation in ulcerative colitis is due to decreased butyrate uptake and a defect in the oxidation pathway. Inflamm. Bowel Dis. 2012, 18, 1127-1136. [CrossRef] [PubMed]

123. Kim, H.; Venancio, V.P.; Fang, C.; Dupont, A.W.; Talcott, S.T.; Mertens-Talcott, S.U. Mango (Mangifera indica L.) polyphenols reduce IL-8, GRO, and GM-SCF plasma levels and increase Lactobacillus species in a pilot study in patients with inflammatory bowel disease. Nutr. Res. 2020, 75, 85-94. [CrossRef] [PubMed]

124. Ashton, J.J.; Colquhoun, C.M.; Cleary, D.W.; Coelho, T.; Haggarty, R.; Mulder, I.; Batra, A.; Afzal, N.A.; Beattie, R.M.; Scott, K.P.; et al. 16S sequencing and functional analysis of the fecal microbiome during treatment of newly diagnosed pediatric inflammatory bowel disease. Medicine 2017, 96, e7347. [CrossRef]

125. Duboc, H.; Rajca, S.; Rainteau, D.; Benarous, D.; Maubert, M.-A.; Quervain, E.; Thomas, G.; Barbu, V.; Humbert, L.; Despras, G.; et al. Connecting dysbiosis, bile-acid dysmetabolism and gut inflammation in inflammatory bowel diseases. Gut 2013, 62, 531. [CrossRef] 
126. Torres, J.; Palmela, C.; Brito, H.; Bao, X.; Ruiqi, H.; Moura-Santos, P.; Pereira da Silva, J.; Oliveira, A.; Vieira, C.; Perez, K.; et al. The gut microbiota, bile acids and their correlation in primary sclerosing cholangitis associated with inflammatory bowel disease. United Eur. Gastroenterol. J. 2018, 6, 112-122. [CrossRef]

127. Morgan, X.C.; Tickle, T.L.; Sokol, H.; Gevers, D.; Devaney, K.L.; Ward, D.V.; Reyes, J.A.; Shah, S.A.; LeLeiko, N.; Snapper, S.B.; et al. Dysfunction of the intestinal microbiome in inflammatory bowel disease and treatment. Genome Biol. 2012, 13, 79. [CrossRef]

128. Oz, H.S.; Chen, T.; de Villiers, W.J. Green tea polyphenols and sulfasalazine have parallel anti-Inflammatory properties in colitis models. Front. Immunol. 2013, 4, 132. [CrossRef]

129. Fujiki, H.; Suganuma, M.; Imai, K.; Nakachi, K. Green tea: Cancer preventive beverage and/or drug. Cancer Lett. 2002, 188, 9-13. [CrossRef]

130. Evans, M.O.; Starley, B.; Galagan, J.C.; Yabes, J.M.; Evans, S.; Salama, J.J. Tea and recurrent clostridium difficile infection. Gastroenterol. Res. Pract. 2016, 2016, 4514687.

131. Leystra, A.A.; Clapper, M.L. Gut microbiota influences experimental outcomes in mouse models of colorectal cancer. Genes 2019 10, 900. [CrossRef] [PubMed]

132. Chen, W.; Liu, F.; Ling, Z.; Tong, X.; Xiang, C. Human intestinal lumen and mucosa-associated microbiota in patients with colorectal cancer. PLoS ONE 2012, 7, e39743. [CrossRef] [PubMed]

133. Liu, M.; Xie, W.; Wan, X.; Deng, T. Clostridium butyricum modulates gut microbiota and reduces colitis associated colon cancer in mice. Int. Immunopharmacol. 2020, 88, 106862. [CrossRef] [PubMed]

134. Ratsimandresy, R.A.; Indramohan, M.; Dorfleutner, A.; Stehlik, C. The AIM2 inflammasome is a central regulator of intestinal homeostasis through the IL-18/IL-22/STAT3 pathway. Cell Mol. Immunol. 2017, 14, 127-142. [CrossRef]

135. Man, S.M.; Zhu, Q.; Zhu, L.; Liu, Z.; Karki, R.; Malik, A.; Sharma, D.; Li, L.; Malireddi, R.K.; Gurung, P.; et al. Critical role for the DNA sensor AIM2 in stem cell proliferation and cancer. Cell 2015, 162, 45-58. [CrossRef] 